\title{
Research of the Micro Class Teaching Application on the Motor and Drive Course
}

\author{
Weimin Chen ${ }^{1, a^{*}}$, Hui Cai ${ }^{1, a}$ and Nan $\mathrm{Xie}^{1, b}$ \\ ${ }^{1} 1$ College of Mechanical and Electrical Engineering, China Jiliang University, Hangzhou, China \\ a c9419@cjlu.edu.cn, ${ }^{b} 905321899 @ Q Q . C O M$ \\ ${ }^{*}$ corresponding author
}

Keywords: Motor and drive; Micro class; Teaching application

\begin{abstract}
With the development of the " Internet plus "era, micro class teaching of practical and theoretical understanding of specialized course teaching has brought great convenience, electric motor and driving electrical engineering as an important professional basic course, we need to pay attention to its teaching quality and teaching effect. In this paper, "Motor and Drive" undergraduate course as an example, expounds the application significance of micro lesson in the course of electric motor and driving, focus on the micro class resources in the construction of micro class knowledge selection, teaching design and micro lesson recording three aspects of the analysis, this study aims to explore the operation method of cable micro class both in the theory and practice of the undergraduate courses and flexible use, and provides a new way of thinking for the curriculum construction and teaching reform of courses, improve the teaching quality of courses.
\end{abstract}

\section{Introduction}

With the "Internet plus" vigorous development, mutual penetration of electrical engineering and automation and traditional various disciplines and cross use more closely, and the "Motor and Drive" is the electrical engineering and automation professional colleges and universities is an important professional basic course. This course focuses on motor and electric drive technology, the motor is widely used in the electric drive system, so the teaching effect directly influences students' employment knowledge, but also makes the teaching is facing a great challenge, especially the micro teaching mode has seeped into universities in various teaching based on the important the significance of innovative teaching method. The application of micro class to the teaching of Motor and Drive courses in undergraduate colleges and universities can greatly improve the efficiency of classroom teaching and the effect of teaching. This paper will explore the application and practice of the new teaching model of micro class in the course of Motor and Drive.

\section{The Significance of the Motor and Drive Micro Class Teaching}

Renewing Teachers' Teaching Ideas and Changing Teaching Methods. The biggest characteristic of the micro lesson is small, under normal circumstances, the micro hour long 10 minutes, start teaching in short time to streamline the effective teaching, and plays an important role in changing the traditional teaching mode of the course. The traditional teaching time is 45 minutes [1-3]. When teachers are teaching, they do not concentrate their time on a knowledge point. Most of the time, students are not fully absorbed. The application of micro lesson in Motor and Drive teaching is not only a way for teachers to transform teaching methods, but also an important strategy to improve students' interest in Motor and Drive courses. First, micro class as a means of turning based on classroom teaching, it is a kind of new teaching mode, fresh students, can attract the attention of students, to stimulate students' learning desire; secondly, the micro class time is short, its application in the electric motor and driving teaching process, can make students to the knowledge in the relaxed environment of middle school, to enhance students' autonomous learning ability; finally, when students have interest in learning, learning objectives will be the new custom, some students will 
advance the teacher's teaching, followed by the micro teaching self-study completed next chapters, and then improve the Motor and Drive the students' application ability and practice ability.

Highlight the Students' Main Position. The traditional classroom teaching is always based on teachers, while students are passively accepting knowledge, so it is difficult to exert their independence and independence in learning knowledge of the motor and drive class. The use of micro teaching mode can improve students' subjective status and improve their autonomous learning ability. Students are more likely to master the key points and difficulties of teaching, and further develop students' divergent thinking ability. First of all, teachers in the curriculum teaching, has always been to establish a student-centered teaching consciousness, improve students' master of thought, carry out teaching activities is to let students master the knowledge of motor theory and practical skills; in addition, teachers in the classroom teaching, can use the micro teaching mode, play students' learning initiative. To create a good learning atmosphere, stimulate students' learning initiative, to enable students to obtain more knowledge of the course of electric motor and driving [4-5]. For example, in the teaching of "Transformers" section, in the micro teaching for 8-10 minutes, after studying the students "structure, the working principle of transformer and transformer equivalent circuit", teachers on-site questions, ask students to describe the stage presentation transformer working principle, and on the blackboard or electronic screen on the scene to draw the equivalent circuit of the transformer, the teacher to the student of the guidance and encouragement, will make the entire classroom learning atmosphere and learning enthusiasm of the students, but also to promote student awareness of independent thinking and active learning.

Help Students to Choose Studying Content. The most important feature of the micro class is the "micro", which is an improvement on the defects of the traditional classroom teaching to develop students' cognitive ability of motor and develop students' practical ability by "micro and meticulous". When developing micro lesson activities, teachers should carefully select the teaching contents of Motor and Drive courses according to their learning level. They should not only show the emphasis and difficulty of teaching, but also conform to students' learning thinking. At the same time, teachers should take into account the coherence and independence of micro class in the design of the teaching content of micro class so as to expect more students' interest in learning.

\section{Micro Class Construction of Motor and Drive}

"Motor and Drive" is a practical course, mainly based on operation and loose connection of knowledge points. Therefore, the key and difficult contents can be separated into independent micro contents, forming micro course resources of course [5-8].

The Selection of the Micro Class Teaching Knowledge. The micro class is based on the teaching video as the main teaching mode, teaching process and related resources around the specific knowledge points. The teaching video time is within 10 minutes. Therefore, the construction of "micro lesson" should first divide the key points and difficult points in the teaching process of motor and drag according to the principle of minimum particle size, that is, a learning object carrying a knowledge point, and then segment it into micro content. The contents of "motor and drag" course can be divided into 4 modules, namely, transformer, DC motor, asynchronous motor and synchronous motor, and the construction of teaching resource database for motor and dragging course is shown in Fig. 1. In the process of resource construction, we should start from the needs of learners, not only considering the independence to each micro class teaching contents, but also considering the logical relationship of the whole knowledge module, and organize every module's content in the form of point to surface. For example, on the part of the DC motor, can be explained from five aspects: the structure and working principle of DC motor, DC motor equivalent circuit, DC motor and DC motor brake and DC motor speed control, this is the five "points" of the DC motor; at the same time, the introduction of "face" test and use DC motor. Arrange six micro class records. In the selection of "point", the principle of minimum granularity is followed, and the logical relationship between points is considered in the content of "face". 


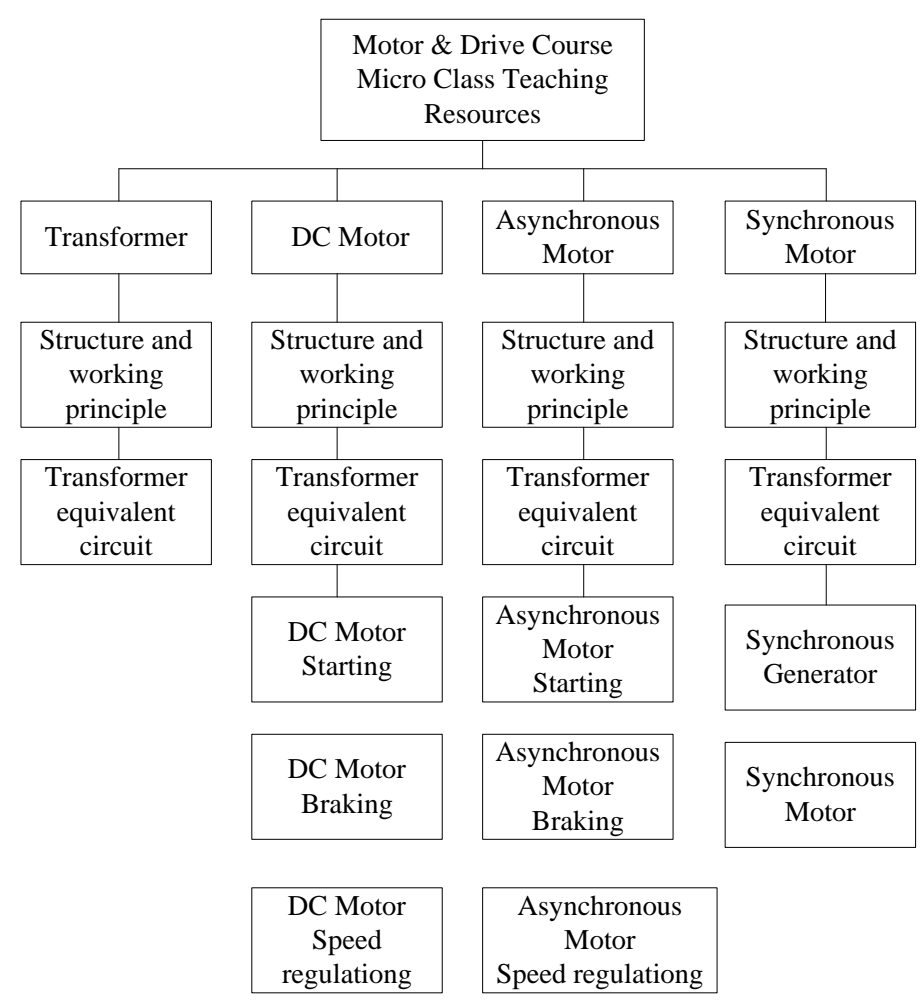

Figure 1. Block diagram of teaching resources for motor and drive micro class

The Micro Class Teaching Design. After defining the content of the construction of the course micro class, the next thing is to design the teaching process. The Authors have been used to practice as the main line, in order to solve this problem, in general, motor and drive course of micro class teaching has been made up of five parts: "introduction problem" and "theory analyzing", "demonstration and operation" and "knowledge summering" and "simulation and practice". The specific implementation follows the following principles: the breakthrough of micro class knowledge quickly, teaching needing clear clues, highlighting the micro class teaching focus, teacher language being appropriate, accurate and logical, simple operation, and the animation demonstration and demo video clips can be combined together [ 8-9]. The Fig. 2 describes the design of the micro class teaching process of the DC motor's working principle. From Fig. 2, we can see that there are six teaching contents and process designs for the Microteaching of the DC motor, which takes about 8 minutes.

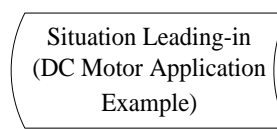

$30 "$

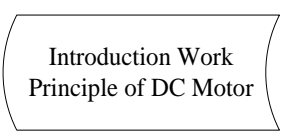

$60 "$

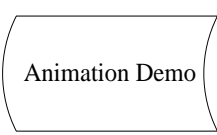

$150 "$

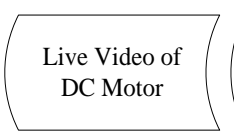

$180 "$

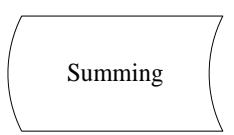

$35^{\prime \prime}$

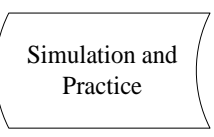

$25 "$

Figure 2. the micro class teaching process of the DC motor's working principle

Micro Class Recording and Editing. At present, the methods of micro class have recording screen recording software, video recording tool for recording, recording room and special software production and IPAD recording. "Motor and Drive" is an equal emphasis on theory and practice of the curriculum, teaching content and explaining the theory analysis, and practical operation and demonstration process, so the use of Camtasia Studio 7 + PPT + Animation + Live Video and other micro class recording and video production, recording operation window size can be set to $720 * 576$. After finishing recording, animation or the completed video clips can complete the late editing of the micro class and finally produce the FLV and MP4 two file formats and upload the convenient resource to network. The micro class resources are uploaded to the course network platform so that the students can download and learn the class from their mobile phones. 


\section{Conclusions}

The new teaching mode of micro class is rising, which has great significance to improving the traditional teaching mode. In the micro class teaching class progress, teachers must accept and adapt to this new teaching mode from the ideological level, so that students can really benefit, not form the style. The micro class teaching mode proposed in this paper has been combined with the learning characteristics of our school, and has been used in the teaching process of Motor and Drive course. Preliminary exploration of motor and drive teaching method has been made, and the construction of micro class resources has been analyzed in detail. Micro class teaching is to make students become the main body of the class, help students to explore knowledge, learn to think independently and solve problems, greatly exert the subjective initiative of students, which can achieve the teaching effect and change the traditional teaching method. And it could achieve certain results in the actual teaching process, and it could provide reference for other university curriculums' implementation during the process of micro class teaching and put forward some innovative ideas for the practical operation and demonstration courses.

\section{References}

[1] Wang Yujia, Wang Xiaojun, Su Xiaoyu. The Exploration of "Motor and Drive Foundation" for the Flipped Classroom [J]. Education Teaching Forum, 2017(01): 251-252.

[2] Li Hongjian, Fu Zhanmin,etc. The application of the micro class based teaching mode in the flipping class -- Taking the course of motor drive and control as an example [J]. China Management Informationization, 2017(08): 243.

[3] Lian Feng, Guo Yanan, Zhang Xinying. A new model of micro lesson teaching based on flipping class -- Taking the course of Motor and Driveging as an example [J]. China Educational Technology \& Equipment, 2017(12): 70-73.

[4] Zhang Yanxia, Zhang Jingjie. Implementation and Promotion on Integration of theory and practice teaching mode in Motor and Drive course [J]. Zhengzhou University of Aeronautics (Social Science Edition), 2016(4): pp. 201-204

[5] Cai Youlan. The application of micro class in the teaching of the basic course of computer application [J]. China Computer \& Communication, 2016(01): 235-236.

[6] Wang Yonggang. The application of micro class in the teaching of Motor and Drive [J]. Era Education, 2016 (13):184-184.

[7] Fang Cheng. The Application of Micro Class in The Teaching Of Motor and Drive [J]. Computer knowledge and technology, 2015(01): 132-133.

[8] Tang Wenjie. Discussion on the application of micro class in Computer Teaching [J]. Asia-Pacific Education, 2016 (09): 68-68.

[9] Yang Yong. Research On The Overall Design Of The Course Of "Motor and Drive Foundation" Based On Project Teaching [J]. Education and Teaching Forum [J], 2014 (07): 233-234,175. 